\title{
One in Five Street Traditional Coffee Vendors Suffered from Depression During the COVID-19 Pandemic in Harar Town, Ethiopia
}

\author{
Mekonnen Sisay (1D \\ Tigist Gashaw $\mathbb{D D}^{\prime}$ \\ Natanim Degefu (iD ${ }^{2}$ \\ Bisrat Hagos (iD) ${ }^{3}$ \\ Addisu Alemu ${ }^{4}$ \\ Zenebu Teshome ${ }^{5}$ \\ Mekonnen Admas (D) \\ Haregeweyn Kibret $\mathbb{D}^{7}$ \\ Yadeta Dessie ${ }^{4}$ \\ 'Department of Pharmacology and \\ Toxicology, School of Pharmacy, College \\ of Health and Medical Sciences, \\ Haramaya University, Harar, Ethiopia; \\ ${ }^{2}$ Department of Pharmaceutics, School of \\ Pharmacy, College of Health and Medical \\ Sciences, Haramaya University, Harar, \\ Ethiopia; ${ }^{3}$ Department of Social \\ Pharmacy, School of Pharmacy, College of \\ Health and Medical Sciences, Haramaya \\ University, Harar, Ethiopia; ${ }^{4}$ Department \\ of Public Health and Health Policy, School \\ of Public Health, College of Health and \\ Medical Sciences, Haramaya University, \\ Harar, Ethiopia; ${ }^{5}$ East Harerge Zone \\ Administration Office, Harar, Ethiopia; \\ ${ }^{6} \mathrm{HIV} / \mathrm{AIDS}$ Unit, Gender, HIVIAIDS and \\ Special Need Affair Directorate, \\ Haramaya University, Harar, Ethiopia; \\ ${ }^{7}$ Department of Nursing, School of \\ Nursing and Midwifery, College of Health \\ and Medical Sciences, Haramaya \\ University, Harar, Ethiopia
}

Correspondence: Mekonnen Sisay Department of Pharmacology and Toxicology, School of Pharmacy, College of Health and Medical Sciences, Haramaya University, P.O. Box, 235, Harar, Ethiopia Email mekonnensisay27@yahoo.com
Background: The COVID-19 crisis has already resulted in an economic and labor market shock and a rise of informal work sectors. Being an informal job, traditional coffee vending can predispose women to a myriad of mental disorders. Therefore, this study was aimed to assess depressive symptoms during the COVID-19 pandemic and associated factors among street traditional coffee vendors in Harar town, Eastern Ethiopia.

Methods: A cross-sectional study was employed on 180 women engaged in street traditional coffee vending business in Harar town. Data were collected through a face-to-face interview using a Public Health Questionnaire and analyzed using SPSS version 20. Binary logistic regression was executed to identify factors associated with depression at a cut-off point of $\mathrm{P}<0.05$.

Results: The mean age of the study participants was $31.83( \pm 10)$ years. The majority of the participants were currently married $(n=77,42.8 \%)$, attended primary education $(n=68,37.8 \%)$, had a family member of four or more $(n=60,33.3 \%)$, and had two years or less work experience $(\mathrm{n}=123,68.3 \%)$. Most of the study participants obtained COVID-19-related information from television ( $\mathrm{n}=125,69.4 \%$ ). The prevalence of depression was found to be $18.9 \%$. Attending primary education (AOR: 0.34; 95\% CI: 0.12, 0.98), attending secondary education or higher (AOR: 0.23 ; 95\% CI: 0.07, 0.69), and having four or more family members (AOR: $2.81 ; 95 \% \mathrm{CI}$ : $1.14,6.92)$ were significantly associated with depression.

Conclusion: One in five street traditional coffee vendors suffered from depression during the COVID-19 pandemic. Lower odds of being depressed were observed in those who attended a minimum of primary education. On the contrary, having a greater family size was associated with higher odds of being depressed. This finding will direct the government and other concerned bodies to be involved in the provision of psychological and material support for such informal workers during COVID-19.

Keywords: coronavirus, depression, street, traditional coffee vending

\section{Introduction}

During the COVID-19 pandemic, healthcare systems had to face a complete reset, ${ }^{1-4}$ both healthcare workers and patients had to perform several preventive strategies, such as donning masks ${ }^{5}$ that have high social ${ }^{6}$ and medical costs. ${ }^{7,8}$ In this scenario, traditional coffee vendors in Ethiopia had to operate and design a completely new vendor-buyer interaction, but its rebound on mental health was not previously evaluated. COVID-19 itself and the health-related measures being taken to mitigate the transmission of the virus has also resulted in a profound physical, social, economic and psychological crisis since its outbreak. ${ }^{9-11}$ 
Historically, studies indicated that such infectious disease outbreaks had resulted in a myriad of mental and psychological disorders including anxiety, depression and insomnia. The combined effects of these disorders can have dire consequences in the future life of survivors, frontline health workers, families and communities of lowincome settings. ${ }^{10,12,13}$ Due to the emerging and gradually evolving nature of the pandemic, it is too difficult to predict the future health risks as well. ${ }^{14}$

Several studies around the world reported a wide range of magnitude of depression among the public since the COVID-19 outbreak. The prevalence of depression among the general population was reported to be $20.1-48.3 \%$ in China, ${ }^{15-17} 22.1 \%$ in the UK, ${ }^{18} 27.8 \%$ in the United States, ${ }^{19} 14.1 \%$ in India $^{20}$ and $67.1 \%$ in Egypt. ${ }^{21}$ In a study done in Addis Ababa, Ethiopia, the prevalence of depression in an urban community was reported to be $12.4 \%$. The study further outlined that gender, monthly income, educational status, number of family members, history of contact, and history of chills and fever were significantly associated with depression. ${ }^{22}$ Beyond this, Roma et al also found that childlessness and the personality dimensions of negativity and detachment were associated with depression while a resilient coping style was negatively associated with depression in a two-month follow-up study of psychological distress among Italian people during the lockdown. ${ }^{23}$

In low-income countries with a high unemployment rate, street vending is actually a source of income for poor dwellers to cover the household costs. ${ }^{24}$ Despite being a shock absorber or natural buffer in crisis situation, the high prevalence of informal markets needs a change in the social protection framework. ${ }^{25}$ They contribute a large share to the national economy and market stability despite having little social protection and a marginalized economy, making them highly vulnerable to government restrictions. ${ }^{26,27}$ In subSaharan Africa the majority of informal workers are facing occupational health and safety concerns even in a normal scenario. The outbreak of COVID-19 led these workers to confront a new challenge as a result of government measures to combat the disease. Although they have demonstrated a promising resilience during the crisis, a multitude of contact points make them highly vulnerable to the disease. ${ }^{28}$ The hand-to-mouth nature of this business has created difficulty in adapting to the context. ${ }^{29,30}$ In these countries, the socioeconomic crisis due to the COVID-19 pandemic also resulted in a myriad of common mental disorders. In light of the fear of COVID-19, financial constraints forced these informal vendors to break the government restrictions. The government could not support these sectors during the crisis time. Besides, the impact of COVID-19 on mental health issues has also been underestimated in these settings. ${ }^{31}$

In many countries, this informal work is positively associated with social inequalities and vulnerabilities due to low wages, lack of labor rights, inadequate health services, and poor housing conditions. Since their work is a matter of survival, they do not quarantine themselves, even they get sick. They are stressed as a result of the economic crisis and risk of infection. There is also a weak social security and poor health service coverage in developing countries. ${ }^{32}$ Besides, there is no clear public health and economic guarantee from the government during hardship. ${ }^{33}$ Therefore, they cannot stop working despite "stay at home" directions forwarded from the government. All these issues might have resulted in a myriad of mental problems in women engaged in traditional coffee vending during this crisis time. ${ }^{34,35}$

Women, in particular, are at increased risk of mental disorders probably due to the lack of social support, high workload/family burden, and poor recognition. ${ }^{36,37}$ In COVID-19 affected areas, women were found to be economically disadvantaged. ${ }^{38}$ In developing countries, women are usually prevented from entering formal sectors in relation to culture, religion, illiteracy, and family obligations. ${ }^{39}$ Accordingly, home-based tasks and street vending are the two major businesses in which women are the overwhelming majority. However, the sector lacks stability, social welfare or representation, and public health guarantees. ${ }^{40-42}$ Given the dearth of research findings addressing the psychological aspects of COVID-19 among women street vendors in Eastern Ethiopia, the present study was aimed to address the prevalence of depressive symptoms among street traditional coffee vendors in Harar town, Eastern Ethiopia.

\section{Methods}

\section{Study Area, Design and Period}

We conducted this study in Harar town, the capital of the Harari region, which is located $525 \mathrm{~km}$ from the capital of Ethiopia, Addis Ababa to the east. The national regional state of Harari (formerly called region 13) is one of the ten ethnically-based regional states of Ethiopia covering the homeland of the people of Harari. It has the smallest land area and population of the Ethiopian regional states. Harari and Oromo are the two official languages of the regional authorities. Based on the 2007 census conducted by the Central Statistical Agency (CSA) of Ethiopia, Harari has a total 
population of 183,415 , of whom 92,316 were men. This region is the only one in Ethiopia where the majority of its population lives in an urban area: $99,368(54.18 \%)$ of the population were urban inhabitants. There are 9 woredas in the region. Under the woreda, there are 19 city kebeles and 17 rural kebeles. ${ }^{43,44}$ A population-based cross-sectional study was employed from 10-30December 2020.

\section{Study Population}

Women who were engaged in street traditional coffee vending business in Harar town were taken as the target population for this study. All women aged 18 years or above, working on street traditional coffee vending in Harar town and available during the data collection period were included.

\section{Sample Size and Sampling Technique}

Since the street vending business is informal, it was difficult to know the actual number of the study population to determine the sample size. Therefore, to increase the statistical power of the study and considering the absence of previous studies in this segment of the population, all street traditional coffee vendors who were available during the data collection were included. A convenient sampling technique was applied to enroll study participants.

\section{Study Variables}

The magnitude of depression among women coffee vendors during COVID-19 was the outcome variable. Sociodemographic factors including age, marital status, religion, family size, educational status, job experience, and daily income were considered as predictors of depression.

Besides, COVID-19-related variables including the source of COVID-19 information and the type of problems faced during the pandemic were taken as supplemental information. However, we removed them from regression analysis as they did not fit the model requirements.

\section{Data Collection Tools and Procedures}

This survey was conducted through a face-to-face interview utilizing interviewer-administered questions prepared in the local language. A pretest was performed on a small number (approximately 5\%) of coffee vendors at Haramaya town to see the feasibility of the tool and consider slight amendments on the questionnaire. Focused training was given to the data collectors about the objective and methods of data collection.

The questionnaire has three major sections. The first section deals with the sociodemographic characteristics addressing pertinent variables, including age, gender, marital status, education level, work experience, family size, and current work status and income level. The income of the participant was determined with local currency (Ethiopian birr). The average exchange rate of United States dollar (USD) to Ethiopian birr was 32.50 (1 USD $=32.50$ ETB) in December 2020.

The second section of the questionnaire revolves around supplemental variables about COVID-19 (eg, source of information, type of problems faced, and selfreported violence). We did not include these variables in the final regression model.

The third and main section of this tool contains questions focusing on depression. The nine-item Patient Health Questionnaire (PHQ-9) was employed to assess the overall depressive symptoms as the validity of the tool was well elucidated in various studies. ${ }^{45-48}$ The tool has demonstrated internal reliability with Cronbach's alpha-value of 0.89 and reliability correlation (test-retest) of $0.84 .{ }^{45}$ In this study, we checked the internal consistency of responses across nine items (scale reliability analysis) and found a Cronbach's alpha-value of 0.81. A metaanalysis indicated that the optimum cut-off point for diagnosing depressive symptoms with PHQ-9 falls between 8 and $11 .{ }^{49}$ In this regard, the measurement has shown a sensitivity and specificity of $88.0 \%$ for the score of 10 and above to detect depression. ${ }^{45,50}$ Besides, a cut-off score of 10 or more resulted in a maximum combined sensitivity and specificity. ${ }^{51}$ Each item is rated on a fourpoint scale (based on severity) ranging from 0 for not at all to 3 for nearly every day. ${ }^{50}$ In this study, the severity of depressive symptoms was grouped based on the overall scores ranging from 0 to 27 and classified as no/minimal (0-4), mild (5-9), moderate (10-14), moderately severe (15-19), and severe depression (20-27). The online version of the questionnaire is available here: https://patient. info/doctor/patient-health-questionnaire-phq- 9 .

\section{Data Processing and Analysis}

The data were double entered into EpiData 3.1 software and exported to Statistical Package for the Social Sciences (SPSS), version 20.0 for data analysis. The univariate analysis was conducted for socio-demographic and other COVID-19 specific variables using frequency, percentage and central tendency measures. The prevalence of depression, as defined by clinical cut-off scores, during the COVID-19 pandemic was determined. The dependent 
variable was dichotomized based on the available scientific evidence to determine depressive symptoms. Bivariate and multivariate binary logistic regression analyses were done with $95 \%$ confidence interval and a p-value of $<0.05$ to declare statistical significance. The final result was interpreted and provided using appropriate summary measures.

\section{Results}

\section{Sociodemographic Characteristics}

The study included 180 street traditional coffee vendors in Harar town. The mean ( \pm standard deviation) age of participants was $31.83( \pm 10.0)$ years. More than twothirds of the study participants $(n=125,69.4 \%)$ were in the age group less than or equal to 35 years. Besides, the majority of the participants were currently married $(\mathrm{n}=77,42.8 \%)$, were Orthodox Christian $(\mathrm{n}=128$, $71.1 \%)$, attended up to primary education $(\mathrm{n}=68$, $37.8 \%)$, had family members of four or more $(n=60$, $33.3 \%)$, had two years or less work experience $(n=123$, $68.3 \%)$, were unemployed $(\mathrm{n}=145,80.6 \%)$ and had a daily income of more than 150 Ethiopian birr (4.61 USD) $(\mathrm{n}=99,55 \%)$ with a median income of 200 ETB (IQR: 100-300) (Table 1).

\section{COVID-19-Related Responses}

Regarding the source of information, most of the study participants obtained COVID-19-related information from television alone $(\mathrm{n}=125,69.4 \%)$ followed by television and telephone $(\mathrm{n}=29,16.1 \%)$. Besides, 100 (55.6\%) participants experienced problems during the COVID-19 outbreak, with the economic problem taking the largest share $(n=89,89 \%)$. About $51.7 \%$ of participants self-reported a feeling of anxiety symptoms. Furthermore, 13 participants reported unexpected workplace violence with verbal violence being three-fourths of it (Table 2).

\section{Stages of Depression}

Depending on the severity rating of depression, 56 (31.1\%), $90(50.0 \%), 32(17.8 \%)$, and $2(1.1 \%)$ participants were categorized with minimal, mild, moderate, and moderately severe depression, respectively. Upon dichotomizing the depressive symptoms to declare clinical depression, about $18.9 \%$ of participants were categorized as clinically depressed (Figure 1).
Table I Sociodemographic Characteristics of Street Coffee Vendors in Harar Town

\begin{tabular}{|c|c|c|c|}
\hline \multicolumn{2}{|l|}{ Variables } & \multirow{3}{*}{$\begin{array}{c}\text { Frequency } \\
125 \\
55\end{array}$} & \multirow{3}{*}{$\begin{array}{c}\% \\
69.4 \\
30.6\end{array}$} \\
\hline Age (y) & $\leq 35$ & & \\
\hline & $>35$ & & \\
\hline \multirow[t]{4}{*}{ Marital status } & Single & 62 & 34.4 \\
\hline & Divorced & 30 & 16.7 \\
\hline & Married & 77 & 42.8 \\
\hline & Widowed & 11 & 6.1 \\
\hline \multirow[t]{4}{*}{ Religion } & Orthodox Christian & 128 & 71.1 \\
\hline & Protestant & 32 & 17.8 \\
\hline & Muslim & 18 & 10.0 \\
\hline & Others & 2 & I.I \\
\hline \multirow[t]{3}{*}{ Educational status } & $\begin{array}{l}\text { Never attend formal } \\
\text { school }\end{array}$ & 27 & 15.0 \\
\hline & Primary education & 68 & 37.8 \\
\hline & $\begin{array}{l}\text { Secondary education and } \\
\text { above }\end{array}$ & 85 & 47.2 \\
\hline \multirow[t]{4}{*}{ Family size } & One & 19 & 10.6 \\
\hline & Two & 46 & 25.6 \\
\hline & Three & 55 & 30.6 \\
\hline & Four and above & 60 & 33.3 \\
\hline \multirow[t]{2}{*}{ Work experience } & Two years or less & 123 & 68.3 \\
\hline & Greater than two years & 57 & 31.7 \\
\hline \multirow{5}{*}{$\begin{array}{l}\text { Purpose of the } \\
\text { job }\end{array}$} & For helping my family & 34 & 18.9 \\
\hline & To get additional money & 14 & 7.8 \\
\hline & To change & 37 & 20.6 \\
\hline & Means of creating work & 18 & 10.0 \\
\hline & Others & 77 & 42.8 \\
\hline \multirow{4}{*}{$\begin{array}{l}\text { Additional work } \\
\text { status }\end{array}$} & Government employee & I & 0.6 \\
\hline & Retiree & 7 & 3.9 \\
\hline & Self-employed & 27 & 15.0 \\
\hline & Unemployed & 145 & 80.6 \\
\hline \multirow[t]{2}{*}{ Daily income } & $\leq 150$ ETB & 81 & 45 \\
\hline & $>150$ ETB & 99 & 55 \\
\hline
\end{tabular}

Abbreviation: ETB, Ethiopian birr.

\section{Factors Associated with Depression During COVID-19}

The bivariate binary logistic regression analysis indicated that being depressed was 2.44 times more likely to occur in participants with the age groups of greater than 35 years. On the contrary, having a higher level of education was significantly and negatively associated with depression. In multivariate analysis, attending primary education (AOR: $0.34 ; 95 \% \mathrm{CI}$ : $0.12,0.98$ ) and secondary education or above (AOR: 0.23; $95 \%$ CI: $0.07,0.69)$ were significantly and negatively associated with depression. On the other hand, having a family size 
Table 2 COVID-19-Related Responses Among Street Coffee Vendors in Harar Town

\begin{tabular}{|l|l|c|c|}
\hline \multicolumn{2}{|l|}{ Variables } & Frequency & $\%$ \\
\hline Source of information & Television & 125 & 69.4 \\
& Radio & 2 & 1.1 \\
& Internet & 3 & 1.7 \\
& Television and & 11 & 6.1 \\
& Internet & & \\
& Television and Radio & 10 & 5.6 \\
& Television and & 29 & 16.1 \\
& Telephone & & \\
\hline Problem faced with & Yes & 100 & 55.6 \\
COVID-19 & No & 80 & 44.4 \\
\hline Type of problems & Economical & 89 & 89 \\
& Mental status & 9 & 9 \\
& Economical and & 2 & 2 \\
\hline Self-reported anxiety & Pes & & \\
\hline Nychological & 93 & 51.7 \\
& No & 87 & 48.3 \\
\hline Unexpected & Yes & 13 & 7.2 \\
workplace violence & No & 167 & 92.8 \\
\hline Type violence & Verbal & 5.6 \\
& Physical & 1.1 \\
\hline
\end{tabular}

of four or more during the COVID-19 outbreak was positively and significantly associated with depressive symptoms (AOR: 2.81; 95\% CI: 1.14, 6.92) (Table 3).

\section{Discussion}

The COVID-19 pandemic not only causes physical health problems but also poses the danger of a myriad of mental disorders. ${ }^{52}$ The extent of the pandemic and its eventual impact on the health and wellbeing of citizens caused fear, anxiety and depressive symptoms. ${ }^{53}$ In this study, we tried to address the magnitude of the depressive symptoms among street traditional coffee vendors during the pandemic. One-third of them had a family size of four or more. Nearly half of the total participants had experienced economical problems during the pandemic. One in nearly five women suffered from clinical depressive symptoms as well. Attending primary education or more and having a large family size were significantly associated with depression.

In a meta-analysis of twelve community-based studies, the prevalence of depression ranged from $7.45 \%$ to $48.30 \%$ with a pooled prevalence being $25 \%$. $^{9}$ Compared with the global pooled prevalence $(3.44 \%)$ in $2017,{ }^{54}$ the pooled estimate $(25 \%)$, as well as the magnitude of depression in our study (18.9\%), appeared to be several folds higher, indicating the profound impact of the COVID-19 outbreak on individual's psychological and mental health. Likewise, the prevalence of anxiety or depression or both was $20.4 \%$ in China $^{55}$ vividly indicating a sharp increase in the prevalence of depression among the general population during the pandemic compared to the $4 \%$ prevalence observed before the outbreak (in 2019). ${ }^{56}$

In line with our findings, the prevalence of depression (PHQ-9 score $\geq 10$ ) was $19.8 \%$ in Hong Kong's general population during the pandemic with the prevalence of having both depression and anxiety being $12.40 \%{ }^{50}$ The prevalence of depression in the Republic of Ireland was found to be $22.8 \%,{ }^{46}$ slightly higher than our finding. The study emphasized that being female and loss of income

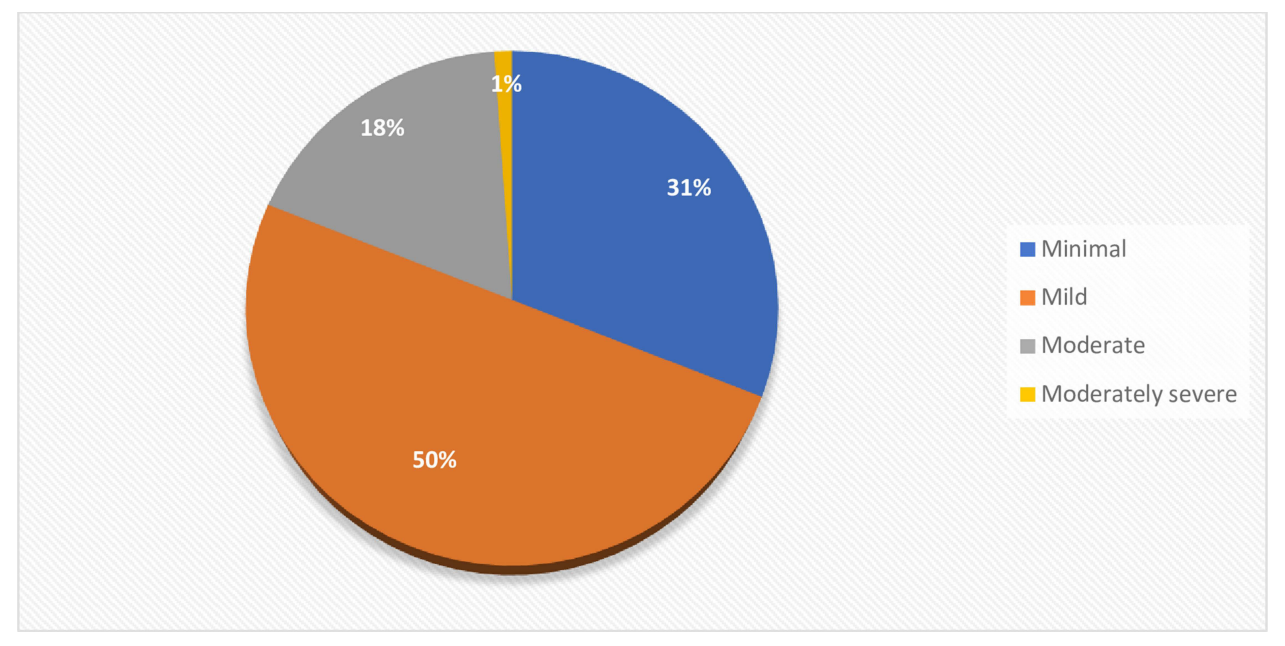

Figure I Stages of depression among street coffee vendors amid COVID-19. 
Table 3 The Association Between Predictor Variables and Depression During COVID-19

\begin{tabular}{|c|c|c|c|c|c|c|c|}
\hline \multicolumn{2}{|l|}{ Variables } & \multicolumn{2}{|c|}{ Depression } & \multirow{3}{*}{$\begin{array}{l}\text { COR }(95 \% \mathrm{Cl}) \\
\mathrm{I} \\
2.44(1.13,5.25)\end{array}$} & \multirow{3}{*}{$\begin{array}{l}\mathbf{p} \\
- \\
0.02 *\end{array}$} & \multirow{3}{*}{$\begin{array}{l}\text { AOR }(95 \% \mathrm{Cl}) \\
\mathrm{I} \\
\mathrm{I} .45(0.57,3.72)\end{array}$} & \multirow{3}{*}{$\begin{array}{l}\mathbf{P} \\
- \\
0.43\end{array}$} \\
\hline & & \multirow{2}{*}{$\begin{array}{l}\text { Yes } \\
18 \\
16\end{array}$} & \multirow{2}{*}{$\begin{array}{l}\text { No } \\
107 \\
39\end{array}$} & & & & \\
\hline Age $(Y)$ & $\begin{array}{l}\leq 35 \\
>35\end{array}$ & & & & & & \\
\hline Marital status & $\begin{array}{l}\text { Not currently married } \\
\text { Currently married }\end{array}$ & $\begin{array}{l}22 \\
12\end{array}$ & $\begin{array}{l}81 \\
65\end{array}$ & $\begin{array}{l}\text { I } \\
0.68(0.31,1.47)\end{array}$ & $\overline{-}$ & & \\
\hline Religion & $\begin{array}{l}\text { Orthodox Christian } \\
\text { Other religions }\end{array}$ & $\begin{array}{l}24 \\
10\end{array}$ & $\begin{array}{l}104 \\
42\end{array}$ & $\begin{array}{l}0.97(0.43,2.20) \\
\text { I }\end{array}$ & $\begin{array}{l}0.94 \\
-\end{array}$ & & \\
\hline Educational status & $\begin{array}{l}\text { Never attend formal school } \\
\text { Primary education } \\
\text { Secondary education and above }\end{array}$ & $\begin{array}{l}10 \\
13 \\
11\end{array}$ & $\begin{array}{l}17 \\
55 \\
74\end{array}$ & $\begin{array}{l}\text { I } \\
0.40(0.15,1.08) \\
0.25(0.09,0.69)\end{array}$ & $\begin{array}{l}- \\
0.07 \\
0.007^{*}\end{array}$ & $\begin{array}{l}\text { I } \\
0.34(0.12,0.98) \\
0.23(0.07,0.69)\end{array}$ & $\begin{array}{l}- \\
0.046 * \\
0.009 *\end{array}$ \\
\hline Family size & $\begin{array}{l}\text { Below four } \\
\text { Four and above }\end{array}$ & $\begin{array}{l}18 \\
16\end{array}$ & $\begin{array}{l}102 \\
44\end{array}$ & $\begin{array}{l}\text { I } \\
2.06(0.96,4.4 I)\end{array}$ & $\overline{-}-$ & $\begin{array}{l}\mathrm{I} \\
2.81(1.14,6.92)\end{array}$ & $\begin{array}{l}- \\
0.024 *\end{array}$ \\
\hline Work experience & $\begin{array}{l}\text { Two years or less } \\
\text { Greater than two years }\end{array}$ & $\begin{array}{l}20 \\
14\end{array}$ & $\begin{array}{l}103 \\
43\end{array}$ & $\begin{array}{l}\text { I } \\
\text { I.67 }(0.77,3.62)\end{array}$ & - & $\begin{array}{l}\text { I } \\
0.99(0.39,2.48)\end{array}$ & $\begin{array}{l}- \\
0.98\end{array}$ \\
\hline Daily income & $\begin{array}{l}\leq 150 \text { ETB } \\
>150 \text { ETB }\end{array}$ & $\begin{array}{l}12 \\
22\end{array}$ & $\begin{array}{l}69 \\
77\end{array}$ & $\begin{array}{l}\text { I } \\
\text { I.64 (0.76-3.56) }\end{array}$ & $\overline{0.21}$ & $\begin{array}{l}\text { I } \\
2.02(0.87,4.69)\end{array}$ & $\overline{0.10}$ \\
\hline
\end{tabular}

Note: *Significant at $\mathrm{p}<0.05$.

Abbeviations: COR, crude odds ratio; AOR, adjusted odds ratio.

due to COVID-19 were positively associated with depression. Despite the low socio-economic index of developing countries like Ethiopia, the decreased fear and anxiety related to looser restrictions compared to the initial wave of the pandemic might have changed the trends of mental disorders. Compared to the Western countries, the COVID-19 impact on Africa was not of the level expected. We also conducted this study just one year after the outbreak and hence adaptation to the changing context might have occurred. A study conducted in the United States general public indicated that the prevalence of depressive symptoms increased three-fold compared to the one before the pandemic Those exposed to stressors and with lower social and economic resources resulted in a greater burden of depressive symptoms. ${ }^{19}$ Results lower than our finding were also reported from China where the prevalence of depression was $11.78 \%$ with $6.56 \%$ cases presenting both depression and anxiety during the pandemic. ${ }^{57}$ This might be ascribed to Chinese experience in remarkably controlling the public health and economic impacts of the pandemic within a short period of time. Also, the government and other concerned bodies should be involved in the provision of tailored psychological and material support for citizens during the crisis period., Compared to our findings, a greater prevalence of depression was reported in Turkey $(23.6 \%)^{58}$ and India (25\%). ${ }^{59}$ Besides, a metaanalysis conducted among the general population in the initial wave of the pandemic showed that the prevalence of depression was found to be $33.7 \%{ }^{52}$ It is also further supported by a study justifying the positive association between depression and/or anxiety symptoms and COVID-19-related stressors in its multivariable logistic regression analysis. ${ }^{60}$

A multimodal depression model, designed in Australia to detect depression dynamics, showed that individuals became more depressed following the COVID-19 outbreak. ${ }^{61}$ Hence, devising a strategy for combating mental health issues during this pandemic should be taken as a prior public health agendum to improve the physical as well as psychological wellbeing of citizens.

Looking at the factors that influence depressive symptoms, large family size was positively and significantly associated with depression, whereas educational status of women was negatively associated with depression. In this regard, the odds of experiencing depressive symptoms were higher in households with four or more persons in Canadian adults during the pandemic $(\mathrm{AOR}=1.88,95 \%$ $\mathrm{CI}=1.14,3.12) .{ }^{62}$ Likewise, a study conducted in South Africa indicated that household economic costs due to large family size was positively and significantly 
associated with depression. ${ }^{63}$ This is obvious in lowincome countries like Ethiopia where there is no economic guarantee during a crisis situation. In light of economic fluctuation and inflation of goods, their daily income from such informal business might not accommodate all household requirements. Hence, household financial wellness can be considered as a protective factor against depression. ${ }^{31,64}$ Regarding educational status of women, a study in Brazil indicated that the maximum risk of depression occurred with women having a lower level of schooling. ${ }^{64}$ Also, studies in Taiwan and China indicated that women with lower educational attainment were likely to experience common mental disorders. ${ }^{65,66}$

\section{Strengths and Limitations of the Study}

There is no previous study addressing the mental health aspects of women in such an informal economic sector where there is a lack of public health and economic guarantee during hardship. The mental health risk of this segment of the population was not assessed so far. We used a standardized data collection format for addressing depressive symptoms. However, the study was not free from limitations. It is a cross-sectional study which could not explore the long-term impact of the problem. Due to the informal nature of the business, small sample size and limited area of coverage with convenient sampling technique may reduce the power of the study for further statistical analysis and inference. This study also focuses on depressive symptoms only and could not address other mental disorders. Furthermore, as this study was conducted at the end of 2020, the initial fear and anxiety was expected to decline as the government had loosened the lockdown restrictions. This might affect the trends of depressive symptoms.

\section{Conclusion}

In this study, one in five street traditional coffee vendors suffered from depressive symptoms during the COVID-19 pandemic in Harar town. Lower odds of being depressed were observed in those who attended a minimum of primary education. On the contrary, having a large family size was associated with higher odds of being depressed. Based on this finding, screening of common mental disorders and tailoring them for appropriate treatment requires due attention by the Ethiopian government and concerned bodies. The government should also provide financial and material support based on the severity of household crisis. The Ministry of Health and other institutions should also provide health education on how to manage such crisis situations. Besides, a long-term plan should be devised to address women working in such informal business sectors through providing public health and economic guarantees during hardship. The government should also have a policy direction focusing on the social protection framework.

\section{Ethical Considerations}

This study was conducted following the Declaration of Helsinki. Before commencing the study, the investigators secured ethical clearance from Haramaya University, College of Health and Medical Sciences Institutional Health Research Ethics Review Committee (IHRERC) with reference number: IHRERC/257/2020. The objectives of the study, as well as the benefits and risks of this research on the participants, was well communicated ahead of the study. Informed, voluntary, written and signed consent was obtained from the participants after the information sheet and consent form was read to them. The confidentiality of the participants information was maintained by making the data collection tool anonymous and using the collected data for this study only. Besides, COVID-19 protective mechanisms were maximized during data collection by keeping a physical distance and providing preventive materials such as face masks and sanitizer.

\section{Author Contributions}

All authors made a significant contribution to the work reported, starting from its conception, study design, execution, and acquisition of data, analysis, and interpretation. Besides, all took part in drafting, revising, or critically reviewing the article; gave final approval of the version to be published; have agreed on the journal to which the article has been submitted; and agree to be accountable for all aspects of the work.

\section{Funding}

Authors disclosed receiving financial support from Haramaya University: Gender, HIV/AIDS, and special needs affair office for conducting this research work.

\section{Disclosure}

The authors have declared no conflicts of interest for this work. 


\section{References}

1. Murray CJ, Abbafati C, Abbas KM, et al. Five insights from the global burden of disease study 2019. The Lancet. 2020;396:1135-1159.

2. Lozano R, Fullman N, Mumford JE, et al. Measuring universal health coverage based on an index of effective coverage of health services in 204 countries and territories, 1990-2019: a systematic analysis for the Global Burden of Disease Study 2019. The Lancet. 2020;396:1250-1284.

3. Gironi LC, Boggio P, Giorgione R. et al. The impact of COVID-19 pandemics on dermatologic surgery: real-life data from the Italian Red-Zone. $J$ Dermatol Treatment;2020. 1-7. doi:10.1080/ 09546634.2020.1789044

4. Pacifico A, Ardigò M, Frascione P, Damiani G, Morrone A. Phototherapeutic approach to dermatology patients during the 2019 coronavirus pandemic: real-life data from the Italian red zone. $\mathrm{Br}$ J Dermatol. 2020;183:375-376. doi:10.1111/bjd.19145

5. Bragazzi NL, Mahroum N, Damiani G, Kong JD, Wu J. Effectiveness of Community Face Mask Use on COVID-19 Epidemiological Trends and Patterns in Italy: Evidence from a "Translational" Study. Taylor \& Francis. Infect Dis. 2021;53:252-254.

6. Kwan RYC, Lee PH, Cheung DSK, Lam SC. Face mask wearing behaviors, depressive symptoms, and health beliefs among older people during the COVID-19 pandemic. Front Med. 2021;8:55. doi:10.3389/fmed.2021.590936

7. Damiani G, Gironi LC, Grada A, et al. COVID-19 related masks increase severity of both acne (maskne) and rosacea (mask rosacea): multi-center, real-life, telemedical, and observational prospective study. Dermatol Ther. 2021;34:e14848. doi:10.1111/dth.14848

8. Damiani G, Gironi LC, Kridin K, et al. Mask-induced Koebner phenomenon and its clinical phenotypes: a multicenter, real-life study focusing on 873 dermatological consultations during COVID19 pandemics. Dermatol Ther. 2021;34:e14823. doi:10.1111/ dth. 14823

9. Bueno-Notivol J, Gracia-García P, Olaya B, Lasheras I, LópezAntón R, Santabárbara J. Prevalence of depression during the COVID-19 outbreak: a meta-analysis of community-based studies. Inte J Clin Health Psychol. 2021;21:100196. doi:10.1016/j. ijchp.2020.07.007

10. Cénat JM, Blais-Rochette C, Kokou-Kpolou CK, et al. Prevalence of symptoms of depression, anxiety, insomnia, posttraumatic stress disorder, and psychological distress among populations affected by the COVID-19 pandemic: a systematic review and meta-analysis. Psychiatry Res. 2021;295:113599. doi:10.1016/j.psychres.2020.113599

11. Cénat JM, Dalexis RD, Kokou-Kpolou CK. Social inequalities and collateral damages of the COVID-19 pandemic: when basic needs challenge mental health care. Int J Pub Health. 2020;65(6):717-718. doi:10.1007/s00038-020-01426-y

12. Keita MM, Taverne B. Depressive symptoms among survivors of Ebola virus disease in Conakry (Guinea): preliminary results of the PostEboGui cohort. BMC Psychiatry. 2017;17(1):127. doi:10.1186/ s12888-017-1280-8

13. Lehmann M, Bruenahl CA, Löwe B, et al. Ebola and psychological stress of health care professionals. Emerg Infect Dis. 2015;21 (5):913-914. doi:10.3201/eid2105.141988

14. Huremović D. Brief history of pandemics (pandemics throughout history). Psychiatry of Pandemics. 2019:7-35.

15. Huang Y, Zhao N. Generalized anxiety disorder, depressive symptoms and sleep quality during COVID-19 outbreak in China: a web-based cross-sectional survey. Psychiatry Res. 2020;288:112954. doi:10.1016/j.psychres.2020.112954

16. Shi L, Lu Z-A, Que J-Y, et al. Prevalence of and risk factors associated with mental health symptoms among the general population in China during the coronavirus disease 2019 pandemic. JAMA Net Open. 2020;3 (7):e2014053-e. doi:10.1001/jamanetworkopen.2020.14053
17. Gao J, Zheng P, Jia Y, et al. Mental health problems and social media exposure during COVID-19 outbreak. PLoS One. 2020;15:e231924. doi:10.1371/journal.pone. 0231924

18. Shevlin M, McBride O, Murphy J, et al. Anxiety, depression, traumatic stress and COVID-19-related anxiety in the UK general population during the COVID-19 pandemic. BJPsych Open. 2020;6(6):6. doi:10.1192/bjo.2020.109

19. Ettman CK, Abdalla SM, Cohen GH, Sampson L. Prevalence of Depression Symptoms in US Adults Before and During the COVID-19 Pandemic. JAMA Net Open. 2020;3:e2019686. doi:10.1001/jamanetworkopen.2020.19686

20. Singh SP, Khokhar A. Prevalence of posttraumatic stress disorder and depression in general population in India during COVID-19 pandemic home quarantine. Asia Pac $J$ Public Health. 2020;33(1):1010539520968455. doi:10.1177/101053952 0968455

21. Arafa A, Mohamed A. Saleh L and Senosy S. Psychological Impacts of the COVID-19 Pandemic on the Public in Egypt. Community Ment Health J. 2021;57:64-69. doi:10.1007/s10597020-00701-9

22. Kassaw C. The magnitude of psychological problem and associated factor in response to COVID-19 pandemic among communities living in Addis Ababa, Ethiopia, March 2020: a cross-sectional study design. Psychol Res Behav Manag. 2020;13:631. doi:10.2147/ PRBM.S256551

23. Roma P, Monaro M, Colasanti M, et al. A 2-month follow-up study of psychological distress among italian people during the COVID-19 lockdown. Int $J$ Environ Res Public Health. 2020;17:8180. doi:10.3390/ijerph17218180

24. Arsene MB, Lebon HM, Maurice KN, Benjamin MB, Faustin BM, Jean-Hélène KK. Understanding the roles of street vendors of agricultural commodities during the COVID-19 outbreak in the informal economy. Open J Soc Sci. 2020;8:115-129.

25. Estupinan X, Sharma M. Job and Wage Losses in Informal Sector due to the COVID-19 Lockdown Measures in India. Available at SSRN 3680379. 2020.

26. Komin W, Thepparp R, Subsing B, Engstrom D. Covid-19 and its impact on informal sector workers: a case study of Thailand. Asia Pac J Soc Work Develop. 2020;1-9.

27. Ferreira Dos Santos G, de Santana Ribeiro LC, Barbosa de Cerqueira R. The informal sector and Covid-19 economic impacts: the case of Bahia, Brazil. Regional Sci Pol Pract. 2020;12:1273-1285. doi:10.1111/rsp3.12366

28. Megersa K. The Informal Sector and COVID-19 in Sub-Saharan Africa. K4D; 2020.

29. Adom D, Adu-Mensah J, Sekyere PA. Hand-to-mouth work culture and the COVID-19 lockdown restrictions: experiences of selected informal sector workers in Kumasi, Ghana. Res $J$ Advan Humanities. 2020;1:45-63.

30. Kiram MZ, Saputra MI The impact of Covid-19 on micro, small, and medium enterprises International Conference on Social Science, Political Science, and Humanities (ICOSPOLHUM 2020). Atlantis Press, 2021, p. 99-103.

31. Salameh P, Aline H, Badro DA, Abou Selwan C. Mental health outcomes of the CoViD-19 pandemic and a collapsing economy: perspectives from a developing country. Psychiatry Res. 2020;294:113520. doi:10.1016/j.psychres.2020.113520

32. Lotta G, Kuhlmann E. When informal work and poor work conditions backfire and fuel the COVID-19 pandemic: why we should listen to the lessons from Latin America. Int $J$ Health Plann Manage. 2020;36(3):976-979. doi:10.1002/hpm.3104

33. Chakraborty S. COVID-19 and women informal sector workers in India. Econ Polit Wkly. 2020;55:17.

34. Joko A The impacts of COVID-19 pandemic to informal economic sector in Indonesia: theoretical and empirical comparison. E3S Web of Conferences. 2020, 03014. 
35. Romero-Michel JC, Mokay-Ramírez KA, Delgado-Machuca M, et al. Health and economic measures in response to the COVID-19 pandemic-Effect on street vendors. J Infect Develop Countries. 2021;15:198-203. doi:10.3855/jidc. 13465

36. Sriharan A, Ratnapalan S, Tricco A, et al. Occupational stress, burnout and depression in women in healthcare during COVID-19 Pandemic: a rapid scoping review. Front Global Women's Health. 2020;1:20. doi:10.3389/fgwh.2020.582463

37. Wade M, Prime H, Johnson D, May SS, Jenkins JM, Browne DT. The disparate impact of COVID-19 on the mental health of female and male caregivers. Soc Sci Med. 2021;275:113801. doi:10.1016/j. socscimed.2021.113801

38. Gashaw T, Hagos B, Sisay M. Expected Impacts of COVID-19: considering Resource-Limited Countries and Vulnerable Population. Front Public Health. 2021;9:614789. doi:10.3389/fpubh.2021.614789

39. Harper C, Marcus R. what can a focus on gender norms contribute to girls'empowerment? Adolesc Girls Dev Countries. 2018;22.

40. Udoh E. Taxing the informal economy in Nigeria: issues, challenges and opportunities. Int J Business Soc Sci. 2015;6:160-175.

41. Becchio G. Behavioral economics, gender economics, and feminist economics: friends or foes? J Econ Methodol. 2019;26:259-271. doi:10.1080/1350178X.2019.1625218

42. Mackie P, Brown A, Dickenson K, Ahmed E, Ahmed Hassan S, Mohamoud Barawani MA. Informal economies, conflict recovery and absent aid. Environ Urban. 2017;29:365-382. doi:10.1177/ 0956247817719868

43. International M. Ethiopia Atlas of Key Demographic and Health Indicators, 2005. Macro International; 2008.

44. HRHB. Harari Reginal State Annnual Bulletin. 2014.

45. Kroenke K, Spitzer RL, Williams JBW. The PHQ-9: validity of a brief depression severity measure. $J$ Gen Intern Med. 2001;16:606-613. doi:10.1046/j.1525-1497.2001.016009606.x

46. Hyland P, Shevlin M, McBride O, et al. Anxiety and depression in the Republic of Ireland during the COVID-19 pandemic. Acta Psychiatr Scand. 2020;142:249-256. doi:10.1111/acps.13219

47. Löwe B, Kroenke K, Herzog W, Gräfe K. Measuring depression outcome with a brief self-report instrument: sensitivity to change of the Patient Health Questionnaire (PHQ-9). J Affect Disord. 2004;81:61-66. doi:10.1016/S0165-0327(03)00198-8

48. Martin A, Rief W, Klaiberg A, Braehler E. Validity of the brief patient health questionnaire mood scale (PHQ-9) in the general population. Gen Hosp Psychiatry. 2006;28:71-77. doi:10.1016/j. genhosppsych.2005.07.003

49. Manea L, Gilbody S, McMillan D. Optimal cut-off score for diagnosing depression with the Patient Health Questionnaire (PHQ-9): a meta-analysis. Cmaj. 2012;184:E191-E6. doi:10.1503/cmaj.110829

50. Choi EPH, Hui BPH, Wan EYF. Depression and anxiety in Hong Kong during COVID-19. Int J Environ Res Public Health. 2020;17:3740. doi:10.3390/ijerph17103740

51. Levis B, Benedetti A, Thombs BD. Accuracy of Patient Health Questionnaire-9 (PHQ-9) for screening to detect major depression: individual participant data meta-analysis. BMJ. 2019;365:365. doi:10.1136/bmj.11476

52. Salari N, Hosseinian-Far A, Jalali R, et al. Prevalence of stress, anxiety, depression among the general population during the COVID-19 pandemic: a systematic review and meta-analysis. Global Health. 2020;16:1-11. doi:10.1186/s12992-019-0531-5
53. Stein MB. COVID-19 and Anxiety and Depression in 2020. Depress Anxiety. 2020;37:302. doi:10.1002/da.23014

54. Ritchie H, Roser M. Mental Health. Our World in Data. University of Oxford, Global Change Data Lab; 2018. https://ourworldindata.org/ mental-health.

55. Li J, Yang Z, Qiu H, et al. Anxiety and depression among general population in China at the peak of the COVID-19 epidemic. World Psychiatry. 2020;19:249. doi:10.1002/wps.20758

56. Huang Y, Wang Y, Wang H, et al. Prevalence of mental disorders in China: a cross-sectional epidemiological study. Lancet Psychiatry. 2019;6:211-224. doi:10.1016/S2215-0366(18)30511-X

57. Chen F, Zheng D, Liu J, Gong Y, Guan Z, Lou D. Depression and anxiety among adolescents during COVID-19: a cross-sectional study. Brain Behav Immun. 2020;88:36-38. doi:10.1016/j. bbi.2020.05.061

58. Özdin S, Bayrak özdin Ş. Levels and predictors of anxiety, depression and health anxiety during COVID-19 pandemic in Turkish society: the importance of gender. Int J Soc Psychiatry. 2020;66 (5):504-511. doi:10.1177/0020764020927051

59. Verma S, Mishra A. Depression, anxiety, and stress and socio-demographic correlates among general Indian public during COVID-19. Int J Soc Psychiatry. 2020;66(8):756-762. doi:10.1177/ 0020764020934508

60. Rudenstine S, McNeal K, Schulder T, et al. Depression and anxiety during the covid-19 pandemic in an urban, low-income public university sample. J Trauma Stress. 2021;34:12-22. doi:10.1002/ jts. 22600

61. Zhou J, Zogan H, Yang S, Jameel S, Xu G, Chen F. Detecting community depression dynamics due to covid-19 pandemic in australia. IEEE Trans Comput Soc Syst. 2021;1-10. doi:10.1109/ TCSS.2020.3047604

62. Wickens CM, Hamilton HA, Elton-Marshall T, Nigatu YT, Jankowicz D, Wells S. Household- and employment-related risk factors for depressive symptoms during the COVID-19 pandemic. Can J Public Health. 2021;112(3):391-399. doi:10.17269/s41997020-00472-6

63. Docrat S, Cleary S, Chisholm D, Lund C. The household economic costs associated with depression symptoms: a cross-sectional household study conducted in the North West province of South Africa. PLoS One. 2019;14(11):e0224799. doi:10.1371/journal. pone.0224799

64. Santos MJD, Kawamura HC, Kassouf AL. Socioeconomic Conditions and Risk of Mental Depression: an Empirical Analysis for Brazilian Citizens. Econ Res Int. 2012;2012:278906. doi:10.1155/ 2012/278906

65. Peng EY-C, Lee M-B, Tsai S-T, et al. Population-based post-crisis psychological distress: an example from the SARS outbreak in Taiwan. J Formosan Med Assoc. 2010;109:524-532. doi:10.1016/ S0929-6646(10)60087-3

66. Xu J, Zheng Y, Wang M, et al. Predictors of symptoms of posttraumatic stress in Chinese university students during the $2009 \mathrm{H} 1 \mathrm{~N} 1$ influenza pandemic. Med Sci Monitor. 2011;17(7):PH60. doi:10.12659/MSM.881836 


\section{Publish your work in this journal}

Neuropsychiatric Disease and Treatment is an international, peerreviewed journal of clinical therapeutics and pharmacology focusing on concise rapid reporting of clinical or pre-clinical studies on a range of neuropsychiatric and neurological disorders. This journal is indexed on PubMed Central, the 'PsycINFO' database and CAS, and is the official journal of The International Neuropsychiatric Association (INA). The manuscript management system is completely online and includes a very quick and fair peer-review system, which is all easy to use. Visit http://www.dovepress.com/testimonials.php to read real quotes from published authors.

Submit your manuscript here: https://www.dovepress.com/neuropsychiatric-disease-and-treatment-journal 